\title{
Redes Sociais e Juventude Rural: apropriações de propostas de Comunicação para o desenvolvimento em redes globalizadas
}

\author{
Nataly de Queiroz Lima* \\ Maria Salett Tauk dos Santos**
}

\section{Resumo}

Este artigo objetiva analisar as apropriações das propostas da Rede de Crianças e Adolescentes Comunicadores de Língua Portuguesa pelos jovens de Nova Olinda, no sertão do Ceará. Especificamente, o que se quer compreender é como os jovens de contexto popular, submetidos à condição contingente de acesso a bens materiais e simbólicos, se apropriam de uma proposta que defende o desenvolvimento local via estratégias de Comunicação acordadas em uma rede social global. A pesquisa combina as teorias dos estudos culturais latino-americanos e dos estudos das redes sociais, via Manuel Castells, Scherer-Warren, Néstor García Canclini, Maria Salett Tauk Santos e Jesus Martin-Barbero. Trata-se de um estudo de caso que utiliza técnicas combinadas de coleta de dados. A pesquisa demonstra que os jovens rurais estão inseridos nas dinâmicas das redes sociais, mas as mediações tecnológicas não são redentoras para a formação de coletivos internacionais.

Palavras chave: Redes sociais. Juventude rural. Tecnologias da Informação e da Comunicação. Internet.

\footnotetext{
* Mestra em Extensão Rural e Desenvolvimento Local da Universidade Federal Rural de Pernambuco, consultora da Agência das Nações Unidas para o Empoderamento da Mulher, professora do curso de Jornalismo, Núcleo de Ciências Humanas e Engenharias da Faculdade Maurício de Nassau- Recife-PE, Brasil, E-mail: queiroz.nataly@gmail.com

** Professora doutora do Programa de Pós-Graduação em Extensão Rural e Desenvolvimento Local da Universidade Federal Rural de Pernambuco, Departamento de Educação, Universidade Federal Rural do Pernambuco-UFRPE, Recife-PE, Brasil.E-mail: mstauk@hotmail.com
}

Intercom - RBCC 


\section{Social Network and Rural Youth: appropriation of communication proposals for development in globalized networks}

\section{Abstract}

This paper aims to analyze the proposed appropriations of the Rede de Crianças e Adolescentes Comunicadores de Língua Portuguesa by young people of Nova Olinda, Ceará. Specifically, the objective is to understand how these youth, subject to the contingent condition of access to material and symbolic, use a proposal that defend the local development via communication strategies on a global social network. this research combines theories of Latin American School of cultural studies and studies of social networks, via Manuel Castells, Scherer-Warren, Néstor García Canclini, Maria Salett Tauk Santos e Jesus Martin-Barbero. This is a case study that using combined techniques of data collection. The research shows that rural youth are embedded in the dynamics of social networks, but the technological mediations are not redemptive for the formation of collectives international.

Keywords: Social Network. Rural Youth. Technology of Information and Comunication. Internet.

\section{Redes sociales y Juventud Rural: apropriaciones de propuestas de comunicación para el desarrollo en redes globalizadas}

\section{Resumen}

Este artículo examina la apropiación de la propuesta de Red de Niños y Adolescentes Comunicadores de Léngua Portuguesa por los jóvenesde Nova Olinda, en el interior de Ceará. En concreto, se quiere entender cómo la juventud de contextos populares, con condiciones contingentes de acceso a bienes materiales y simbólicos, se apropian de una propuesta que aboga por el desarrollo local, a través de estrategias de comunicación acordadas en una red social global. La investigación combina las teorías de los estudios culturales latinoamericanos y estudios de las redes sociales, a través de Manuel Castells, Scherer-Warren, Néstor García Canclini, Maria Salett Tauk Santos y Jesús Martín Barbero. Se trata de un estudio de caso que utiliza técnicas combinadas de recolección de datos. La investigación muestra que la juventud rural se inserta en la dinámica de las redes sociales, pero las mediaciones tecnológicas no son la redención para la formación de colectivos internacionales.

Palabras clave: Redes sociales. Juventud Rural. Tecnología de la Información e Comunicación. Internet.

\section{Introdução}

E

ste artigo tem como objetivo analisar as apropriações das propostas da Rede de Crianças e Adolescentes Comunicadores de Língua Portuguesa pelos jovens de Nova Olinda, 
no sertão do Cariri cearense. Especificamente, o que se quer compreender é como os jovens de contextos populares, que vivem em situação de pobreza, submetidos à condição contingente de acesso a bens materiais e à participação social em esferas rurais, se apropriam de uma proposta que defende o desenvolvimento local, via estratégias de Comunicação acordadas em uma rede social globalizada.

A Rede de Crianças e Adolescentes Comunicadores de Língua Portuguesa tem como objetivo promover intercâmbios e fortalecer experiências de Comunicação para o desenvolvimento local coordenadas por jovens em Angola, Moçambique e Brasil. Neste último país, a iniciativa é liderada pela Fundação Casa Grande, organização não governamental localizada na cidade de Nova Olinda, no Ceará, onde crianças, adolescentes e jovens atuam como produtores de conteúdo e comunicadores comunitários na Rádio Casa Grande FM.

Os jovens do município de Nova Olinda convivem num cenário de desigualdade de oportunidades de acesso a bens materiais, simbólicos e direitos universais como a educação e o direito à informação. O Censo Educacional 2009, realizado pelo Instituto Nacional de Estudos e Pesquisas Educacionais do Ministério da Educação aponta que, na localidade, existem 2.777 estudantes matriculados no ensino fundamental e 697 no ensino médio (NOVA..., 2008), sendo a taxa de analfabetismo da população acima de 15 anos, 34,2\% (TAXA..., 2009). Paralelamente, faltam políticas públicas de geração de emprego e renda, de cultura e de lazer. A maior parte das informações acessadas pela população local advém das parabólicas que transmitem conteúdos de realidades distintas, de outras regiões do país.

A realidade de necessidades imediatas da juventude rural em Nova Olinda é contrastada pela proposta da Fundação Casa Grande cuja intervenção pretende: "levar 'o mundo ao sertão'. Mas não qualquer mundo, e sim um mundo que proporcione as crianças e jovens o empoderamento da cultura e da cidadania" (MISSÃO..., 2008). A organização não governamental mantém o que intitulam de "laboratórios de conteúdos", o que corresponde a videoteca, biblioteca, gibiteca e outros acervos históricos disponíveis para 
consulta da população local e visitantes, e os "laboratórios de produções”, do qual fazem parte a produtora de TV 100 Canal, a Rádio Casa Grande FM, a editora Casa Grande e o teatro Violeta Arraes.

Para fortalecer a iniciativa, os jovens da Fundação Casa Grande, desde 2000, têm participado de redes sociais internacionais. A primeira experiência foi com a Rede de Crianças e Jovens Comunicadores de Língua Portuguesa. Atualmente, eles já integram mais dois coletivos internacionais, um de turismo comunitário e outro de produtores musicais. De acordo com o jovem A.S.:

A Fundação Casa Grande é uma rua diferente. É o único espaço de lazer e de cultura que temos na cidade. As escolas visitam esse espaço, os moradores ouvem a rádio, outros jovens vêm para conhecer a videoteca. Por isso, a troca de conhecimentos com outras realidades é importante. Trazemos para a rádio músicas de outros países, levamos para a banda sons, batidas de outros países. Com isso, a população que frequenta a Fundação pode ter mais cultura e saber que o mundo é grande. Maior do que a nossa cidade (A.S, 2010) ${ }^{1}$.

O depoimento do jovem e as condições sócio-econômicas de Nova Olinda apontam para o desafio de se perceber a complexidade das intervenções junto aos jovens rurais na sociedade da informação. De acordo com Castells (2009), este paradigma se difere das revoluções anteriores, colocando a informação em lugar preponderante. As novas tecnologias são pensadas para gerir fluxos comunicacionais, ampliá-los e difundi-los. A tecnologização da vida se apresenta como uma forma de sociabilidade, de participação e de inserção na vida social. Existir e estar incluído socialmente aparecem como sinônimos de acessar informações, que são produzidas em um ritmo intermitente; de produzir conteúdos, com a emergência de softwares livres que permitem editar gratuitamente blogs e do que alguns pesquisadores têm chamado de jornalismo cidadão, ou seja, os registros em câmeras de celular que são enviados para redações jornalísticas, entre outros; e a participação em redes sociais. Um movimento repleto de paradoxos, em especial para a juventude, como pontua Martin-Barbero:

\footnotetext{
${ }^{1}$ Entrevista concedida por A.S. no dia 08 de janeiro de 2010, na cidade de Nova Olinda, Ceará.
} 
REDES SOCIAIS E JUVENTUDE RURAL

Estamos diante de uma juventude que possui mais oportunidade de alcançar a educação e a informação, porém muito menos acesso ao emprego e ao poder; dotada de maior aptidão para mudanças produtivas, mas que acaba sendo, no entanto, a mais excluída desse processo; com maior afluência ao consumo simbólico, mas com forte restrição ao consumo material; com grande senso de protagonismo e autodeterminação, enquanto a vida da maioria se desenvolve na precariedade e na desmobilização; e por fim, uma juventude mais objeto de políticas do que sujeito-ator de mudanças (MARTIN-BARBERO, 2008, p.12).

Característica do atual paradigma de sociedade, as redes sociais - tecnológicas, virtuais, presenciais ou comunitárias - estão presentes no cotidiano de quase toda a população mundial, mas a dinâmica de negociação de sentidos e os usos de bens materiais e culturais são campos de disputa entre hegemonia e contra-hegemonia, resignificações e rejeições. Segundo Castells, a adaptabilidade das redes à dissolução dos antigos conceitos de tempo e espaço parece ser sua mola motriz:

A morfologia da rede parece estar bem adaptada à crescente complexidade de interação e aos modelos imprevisíveis do desenvolvimento derivado do poder criativo dessa interação. (...) Essa lógica de redes, contudo é necessária para estruturar o não estruturado, porém preservando a flexibilidade, pois o não estruturado é força motriz da inovação na atividade humana (CASTELLS, 2009, p.108).

São elementos característicos das redes, a auto-regulação e a não-linearidade. A capacidade de capilarização presente nos fluxos informacionais e de amplificação sem fronteiras das vozes e ideologias de determinados grupos podem exemplificar tais ponderações.

A rede, como qualquer outra invenção humana, é uma construção social. Indivíduos, grupos, instituições ou firmas desenvolvem estratégias de toda ordem (políticas, sociais, econômicas e territoriais) e se organizam em rede. A rede não constitui o sujeito da ação, mas expressa ou define a escala das ações sociais. As escalas não são dadas a priori, porque são construídas nos processos. Como os objetos são conflituosos, as escalas são ao mesmo tempo objeto e arena de conflitos (DIAS, 2007, p.23).

O desenvolvimento das novas tecnologias e do funcionamento dos mercados financeiros impulsionou os estudos sobre as redes.

Intercom - RBCC

São Paulo, v.35, n.2, p. 225-246, jul./dez. 2012

229 
O tema ganhou relevância na década de 70 , na qual se estruturou um campo de estudo intitulado social network analysis. "Esse paradigma de análise de redes parte do pressuposto de que a vida de cada indivíduo depende em grande medida da forma que se encontra ligado a um amplo espectro de conexões sociais dentro de uma estrutura sistêmica (SCHERER-WARREN, 2007, p.33)".

De acordo com Martin-Barbero, o mundo atual é constituído por "redes e fluxos". Se por um lado, o fenômeno das redes enfraquece as fronteiras nacionais, por outro promove pontos de contato e interações globais que, a sua vez, terminam por ativar capacidades locais.

O novo sentido que o local começa a ter nada tem de incompatível com o uso das tecnologias comunicacionais e das redes informáticas. Hoje essas redes não são unicamente o espaço no qual circulam o capital, as finanças, mas também "um lugar de encontro" de multidões de minorias e comunidades marginalizadas ou de coletividades de pesquisa e trabalho educativo ou artístico. Nas grandes cidades, o uso das redes eletrônicas têm permitido a criação de grupos que, virtuais em sua origem, acabam territorializando-se, passando da conexão ao encontro e do encontro à ação (MARTIN-BARBERO, 2003, p59).

As redes sociais, pelas suas capilaridades, acentuam os processos globalizadores, mas considerando os aportes de Boaventura de Sousa Santos, tais processos não são homogêneos ou isentos de conflitos. Cada sociedade se apropria, recria ou rejeita símbolos e bens hegemônicos, fazendo com que não exista uma única globalização e sim, globalizações (SANTOS, 2003).

Em uma sociedade cada vez mais interconectada, o local funciona como "caixa de ressonância" do global. É o que Canclini chama de "reordenamento das diferenças e desigualdades" sem sua supressão. Trata-se de apropriações e usos de ferramentas globais, as quais podem ser refuncionalizadas para atender a uma demanda local ou utilizadas em uma lógica identitária própria.

Localizados em uma cidade onde os resquícios da cultura patriarcal reveza no poder político o mesmo clã familiar há mais uma década, eles vivenciam a escassez de intervenções governamentais em prol do desenvolvimento local e da ampliação de suas 
oportunidades de crescimento pessoal. Apesar de explorarem as possibilidades das convergências tecnológicas, de tentarem promover a mobilização social, via estratégias de Comunicação para o desenvolvimento local e inclusão em redes sociais internacionais, os jovens de Nova Olinda convivem ainda com uma contrastante realidade de desfavorecimento em relação ao acesso à riqueza do mundo, como acesso à educação, à informação e ao lazer criativo.

É nesse sentido que a pesquisa se volta à análise das apropriações que os jovens da Fundação Casa Grande fazem das propostas da Rede de Criança e Adolescentes de Língua Portuguesa a partir das seguintes perguntas de pesquisa:

1. Como se dá a interação social desses jovens mediada pelas tecnologias e envolvendo jovens rurais de realidades distintas (Brasil, Moçambique e Angola)?

2. Se e de que maneira o trabalho de Comunicação em rede destes jovens se articula com estratégias de Comunicação para o desenvolvimento local?

\section{A pesquisa}

A fundamentação teórico-metodológica do presente estudo está focada na perspectiva dos estudos culturais latino-americanos que privilegia as culturas populares nos processos de hibridização com a cultura de massas e a cibercultura. A ênfase é dada aos usos e as apropriações que fazem as culturas populares em relação às práticas midiáticas hegemônicas. Tal itinerário se faz necessário para a apropriação da amplitude do tema das redes sociais, principalmente quando são globais e se utilizam das mediações tecnológicas para promover a integração de sujeitos de realidades distintas. Como destaca Tauk Santos: "a pesquisa de recepção não se limita a apenas processos diretamente ligados às mídias. A recepção é entendida como um processo em que existe um contrato de Comunicação proposto por organizações governamentais, não governamentais ou a mídia e uma determinada população (TAUK SANTOS, 2006, p.110)".

Nos anos de 1980, os estudos de recepção estavam centrados na análise do impacto dos produtos mediáticos nos receptores, na 
eficiência dos veículos de Comunicação (canal) e das mensagens para convencer as audiências. Na década seguinte, é ampliado o olhar sobre o receptor, o qual se desloca do histórico papel passivo e passa a ser considerado como sujeito ativo do processo de decodificação dos significados das informações veiculadas e das interações mediáticas. Orozco considera que na atualidade os estudos de recepção estão centrados no debate epistemológico, abrindo o leque de temas para compreender a diversidade e a complexidade da contemporaneidade:

Del mero interés por conocer lo que sucede frente a las pantallas o las gratificaciones individuales de los receptores, se ha pasado a una búsqueda por entender los usos sociales de la comunicación y la producción de sentido en general y de manera pormenorizada. La creación simbólica y la producción de sentido en general y de manera pormenarizada. La creación simbólica y la producción cultural en general y en especial la conformación de las culturas políticas de los receptores, han sido vetas de especial atención en los ER contemporáneos. Más recientemente se han empleado ER para conocer la conformación y la reconstitución de identidades de los sujetos receptores, dentro de un esfuerzo por explorar la constitución de la sociedad contemporánea y la creación cultural global y localizada (GÓMEZ, 2002, p.20).

Os estudos de recepção, como destaca Maria Immacolata Vassallo de Lopes, se constituem em uma perspectiva de investigação, articuladora do conjunto do processo da Comunicação:

\begin{abstract}
A recepção é, antes de mais nada, uma perspectiva de investigação e não uma área de pesquisa sobre mais um dos elementos que compõem o processo de Comunicação, neste caso, o público. Não se trata de substituir a análise da "produção", da "mensagem" ou do "canal" pela da "recepção". Firmamos aqui uma perspectiva integradora e compreensiva do estudo da recepção, uma vez que todo o processo de Comunicação é articulado a partir das mediações (LOPES, 1997, p.152).
\end{abstract}

Gómez (2002) ainda destaca que destas preocupações se desdobram múltiplas mediações. Isto porque a construção do sentido de uma determinada mensagem depende de fatores diversos como a subjetividade, as crenças, as relações de classe, de gênero, entre outras. No paradigma da sociedade da informação, a diversidade de interações sociais mediatizadas por novas tecnologias de in- 
formação e Comunicação requer uma aproximação do objeto de estudo. Assim, "são as circunstâncias do objeto que oferecem as pistas para que o pesquisador capte a mediação 'por excelência', isto é, aquela ou aquelas cuja interferência afeta de maneira singular o processo de Comunicação. Nesta perspectiva, a mediação é algo construído em cada caso (TAUK SANTOS, 2006, p.110)”.

Há que se considerar que a perspectiva das mediações culturais, mesmo em tempos de cibercultura se mantém atual, pois como assinala Knewitz: “(...) com o reconhecimento das mediações culturais e com o surgimento de novas tecnologias, mídias e novas formas de subjetivação, restaura-se o interesse acerca do receptor, e emerge a necessidade de revisitar conceitos e métodos utilizados em sua compreensão (KNEWITZ, 2009, p.02)".

Silvaldo Pereira Silva (2007) situa os estudos de recepção a partir de vetores-chaves recorrentes nas pesquisas empíricas em cibercultura e Comunicação. São eles: design, conteúdo, apropriação e fluxo comunicativo. Esta pesquisa localiza-se no vetor da apropriação que, conforme a concepção de Silva, diz respeito a "como o conjunto de indivíduos consome o conteúdo ordenado no médium e quais as repercussões sociais disto (SILVA, 2007, p. 10 apud KNEWITZ, 2010, p.06)".

No caso em estudo, que se insere numa perspectiva de cibercultura, há que se considerar que as apropriações da proposta da Rede de Crianças e Adolescentes Comunicadores de Língua Portuguesa se dá no âmbito de uma trama comunicacional que se estabelece entre os jovens de Nova Olinda, a Fundação Casa Grande e os jovens africanos, na qual existem diferentes níveis de mediação, dentre as quais tem que ser levado em conta as características do novo modelo de sociabilidade engendrado pela cibercultura e as condições concretas de existência dos jovens de Nova Olinda. Os jovens de Nova Olinda, oriundos de contexto popular, eles trazem em suas vivências cotidianas características da desigualdade e da contingência no acesso aos bens de consumo culturais e materiais. Além destas contingências, Os jovens africanos, por sua vez, além destas contingências enfrentam resíduos do medo advindo das recentes guerras recentes presentes na cultura afro-contemporânea. A Fundação Casa Grande que tenta neutralizar estas diferenças, 
contornando a realidade cotidiana em que acham-se envolvidas estas populações, propondo caminhos diferentes - muito além das possibilidades reais - que, tradicionalmente enquanto populações de contextos populares rurais, poderiam adotar. Desta forma, as mediações que se evidenciaram, desde o início do estudo, foram a contextual, as condições concretas do contexto onde vive e atuam estes jovens, e a institucional, expressa na filosofia de trabalho da Casa Grande cuja proposta parece uniformizar as percepções sobre a produção cultural e a própria visão de mundo destes jovens a um patamar de cultura mundializada. Tal processo visa a promoção da cultura local desde que incorpore elementos que atendam a uma estética mundializada.

Assim, esta pesquisa tem caráter qualitativo e analítico. Trata-se de um estudo de caso que incluiu técnicas combinadas de coleta de dados, análise documental, bibliográfica e observação de cunho etnográfico. Para tal se realizou pesquisa bibliográfica, análise documental dos projetos da Rede de Crianças e Adolescentes Comunicadores de Língua Portuguesa e da Fundação Casa Grande, elaboração de dois roteiros de entrevista semi-estruturadas, transcrição das entrevistas e sistematização do material adquirido.

O primeiro roteiro foi direcionado aos jovens e se dividiu em quatro blocos. O primeiro, voltado à identificação e caracterização sócio-econômica; o segundo abordou os conhecimentos dos entrevistados em relação às propostas da Fundação Casa Grande e da Rede de Crianças e Adolescentes Comunicadores de Língua Portuguesa; o terceiro voltou-se às percepções e participação destes jovens na rede internacional; e o quarto, buscou compreender as suas percepções acerca da sua participação no desenvolvimento local de Nova Olinda.

O segundo roteiro de entrevista foi direcionado ao coordenador da Fundação Casa Grande e se dividiu em três blocos: a identificação do entrevistado; a missão e o trabalho da Fundação Casa Grande, assim como a proposta do trabalho em redes sociais; além das estratégias de Comunicação para o desenvolvimento local coordenadas pela Organização.

A pesquisa foi desenvolvida entre janeiro de 2010 e janeiro de 2011. 


\section{Nova Olinda, o lugar da pesquisa}

A cidade de Nova Olinda, lócus desta pesquisa, está situada na Chapada do Araripe, no Ceará, compondo o conjunto de municípios que fazem parte da Região Metropolitana do Cariri (Juazeiro do Norte, Crato, Barbalha, Caririaçu, Farias Brito, Missão Velha, Jardim, Nova Olinda e Santana do Cariri). De acordo com os dados iniciais do Censo 2010 (RESULTADOS..., 2010), do Instituto Brasileiro de Geografia e Estatística (IBGE), a cidade possui 14.256 habitantes, distribuídos em $284 \mathrm{Km}^{2}$ de área territorial.

A cidade convive com um cenário de marcante desigualdade e concentração de renda. Segundo o Instituto de Pesquisa Econômica do Ceará (IPECE), a População em Idade Ativa (PIA), constituída por pessoas residentes de 10 anos e mais, correspondia em 2000 , a $76,88 \%$ do total dos moradores. Cerca de $85,29 \%$ destes se encontravam inseridos nas classes de rendimento de até um salário mínimo, em contraponto à participação dos extratos de rendimento mais elevados com faixas entre 10 a 20 salários mínimos, correspondente a $0,47 \%$ e que recebem mais de 20 salários mínimos, referente a $0,3 \%$ da PIA.

Dados da Pesquisa Nacional por Amostra de Domicílio (IBGE2007) aponta que $24,88 \%$ dos residentes eram jovens entre 15 e 29 anos. É valido salientar que o conceito de juventude que utilizamos nesta pesquisa coincide com o da Cepal (15 a 29 anos).

É neste contexto que foi inaugurada em 1992, a ONG Fundação Casa Grande. A sua criação está vinculada ao resgate histórico das populações que habitavam a cidade de Nova Olinda e também à memória das famílias tradicionais do local. A ideia inicial dos seus diretores e fundadores, o casal Alemberg Quindins e Rosiane Limaverde, músico e historiadora, respectivamente, limitava-se à criação e manutenção de um museu composto por um acervo de registros arqueológicos da tribo kariús-kariris, doados por universidades ou por donos de propriedades do local, assim como pela catalogação de lendas e mitos típicos da região. De acordo com Limaverde: "Nosso primeiro objetivo era, e ainda é, preservar viva a memória do povo do Cariri. O reconhecimento 
de quem somos é importante para valorizar o nosso território (LIMAVERDE, 2010)".

\section{Os jovens em estudo}

Atualmente, a ONG desenvolve ações de Comunicação que estão subdivididas por laboratórios: Web, televisão, rádio, música, teatro e editora. Também mantêm a Cooperativa de Pais e Amigos da Fundação Casa Grande (Copagran) responsável pelo gerenciamento de uma lojinha e de pousadas domiciliares.

O grupo de entrevistados sobre o qual nos debruçamos nesta pesquisa é composto por seis jovens integrantes da Fundação Casa Grande, sendo cinco do sexo masculino e uma do sexo feminino, com faixa etária entre 17 e 26 anos. Apesar de atuarem no mesmo projeto social, o grupo é heterogêneo no que diz respeito às atividades desenvolvidas no interior da organização não governamental, assim como nos seus interesses e perspectivas profissionais. Dois coordenam as atividades de produção musical da Banda que possui nomenclatura homônima; um atua na Rádio Casa Grande FM; um coordena o laboratório de informática e a Editora Casa Grande, responsável pela produção e atualização das peças de Comunicação institucionais; um é responsável pelo laboratório de TV, o qual produz documentários, vídeos e clipes. A entrevistada desta amostra, no final do ano passado (2010), saiu da ONG para trabalhar em uma gráfica local, mas também atuava na Editora. Todos estão envolvidos nas atividades da Rede de Crianças e Adolescentes Comunicadores de Língua Portuguesa.

É válido salientar que, apesar de estarem ocupando os espaços de coordenação dos citados laboratórios, os jovens transitam pelos outros espaços no interior da Fundação. Por exemplo, elaboram documentários, mas também produzem programas de rádio; compõem trilhas musicais e ministram capacitações de informática. A similaridade é que todos produzem e apresentam programas na Rádio Casa Grande FM. Este é o primeiro veículo de Comunicação acessado pelos jovens ao entrar na organização não governamental,

2 Entrevista concedida por Roseane Limaverde no dia 08 de janeiro de 2010, na cidade de Nova Olinda, Ceará. 
além de ser, ao que parece, o mais conhecido pelos moradores da localidade. Como narrou o jovem H.F: "Aqui, a rádio é a boca da Casa Grande e a meninada daqui quer estar na rádio" ${ }^{3}$. Reitera- se que a ONG se apresenta como uma escola de Comunicação. Deste viés, surge a multidirecionalidade das produções dos jovens.

No que diz respeito à escolaridade, quatro entrevistados estão cursando o ensino superior nas áreas de Artes, Educação e Engenharia, tendo dois interrompido temporariamente, o curso universitário pela incompatibilidade de horário com o trabalho. Os outros dois jovens concluíram o ensino médio. Ambos pretendem cursar uma universidade futuramente. Durante as entrevistas, foram apontadas como principais dificuldades para a juventude de Nova Olinda se inserir e se manter na universidade: a necessidade de trabalhar para complementar a renda familiar; a distância das unidades universitárias, que ficam em outros municípios vizinhos, estando o mais próximo a $25 \mathrm{~km}$ da cidade; e o que denominaram de "desestímulo" para seguir estudando.

O cenário de contingências é particular a esta parcela da população, intitulada de juventude rural.

O estudo da juventude rural supõe a compreensão de uma dupla dinâmica social. Por um lado, uma dinâmica espacial que relaciona a casa (a família), a vizinhança (a comunidade local) e a cidade (o mundo urbano-industrial). Mais do que espaços distintos e superpostos, trata-se essencialmente dos espaços de vida que se entrelaçam e que dão conteúdo à experiência dos jovens e à sua inserção na sociedade. Por outro lado, nestes espaços a vida cotidiana e as perspectivas para o futuro são imbuídas de uma dupla dinâmica temporal: o passado das tradições familiares - que inspira as práticas e as estratégias do presente e do encaminhamento do futuro; o presente da vida cotidiana - centrado na educação, no trabalho e na sociabilidade local e o futuro que se expressa, especialmente, através das escolhas profissionais, das estratégias matrimoniais e de constituição patrimonial, das práticas de herança e sucessão e das estratégias de migração temporária ou definitiva. As relações sociais se constroem no presente, inspiradas nas tradições familiares e locais - o passado - e orientam as alternativas possíveis ao futuro das gerações jovens e à reprodução do estabelecimento familiar (WANDERLEY, 2007, p.23).

\footnotetext{
${ }^{3}$ Entrevista concedida pelo jovem H.F. no dia 06 de janeiro de 2011, na cidade de Nova Olinda, Ceará.
}

Intercom - RBCC

São Paulo, v.35, n.2, p. 225-246, jul./dez. 2012 
No que concerne ao mercado de trabalho, foi possível observar que a maioria está ocupada em alguma atividade laboral, no entanto nenhum deles é o principal mantenedor da casa em que moram, e apenas um possui uma relação trabalhista formal, com carteira assinada e direitos assegurados. Apesar de alguns terem familiares próximos, como pais, tios ou avós, atuando na agricultura e criação de animais, nenhum dos jovens tem vínculos diretos com estas atividades, e nem mesmo, pelas respostas ao roteiro de entrevista aplicado, planejam desenvolver trabalhos nestas áreas.

As atividades remuneradas que desenvolvem estão relacionadas intrinsecamente às atividades que executam na Fundação Casa Grande e os conhecimentos adquiridos neste local. Metade dos entrevistados possui como principal fonte de renda uma bolsa concedida pela ONG, por meio de financiamento do Ministério da Cultura, para serem educadores e mobilizadores do pontão de cultura $^{4}$, sediado pela organização. Um trabalha como freelancer, diagramando peças de Comunicação para estabelecimentos comerciais da cidade; há uma jovem que trabalha fora da organização, em uma gráfica, e um que não possui renda mensal, mas atua na Rádio Casa Grande FM e passa todo o dia na instituição.

Um traço marcante é o fato das atividades estarem vinculadas a novas mídias e tecnologias. Os três jovens que são bolsistas da Fundação também atuam como freenlancer, produzindo eventos, documentários, trilhas sonoras e montagem de espetáculos para contratantes como SESC e Banco do Nordeste do Brasil (BNB), que têm sede em cidades próximas como Crato e Juazeiro do Norte. Os outros dois desenvolvem trabalhos de design e programação visual. Nenhum, no entanto, relata planos de ir morar em outro lugar, apesar de ser recorrente, em seus discursos, a vontade de conhecer novos países e mesmo outros estados do país. Desejo ampliado pela participação nas redes sociais internacionais, das quais a $O N G$ integra.

\footnotetext{
${ }^{4}$ O Pontão de Cultura faz parte do Programa Cultura Viva, desenvolvido pelo governo federal, através do Ministério da Cultura. Tratam-se de entidades que recebem apoio institucional e financeiro para coordenar a realização de ações de impacto sócio-cultural em um conjunto de comunidades.
} 
REDES SOCIAIS E JUVENTUDE RURAL

A Fundação faz com que a gente tenha acesso ao mundo com todas as ferramentas para uma boa formação pessoal e coletiva, não só profissional. Os trabalhos dão a possibilidade de fazer o que a gente gosta e ter visibilidade sem precisar sair daqui (S.S., 2011) 5 .

\section{Os jovens e a participação na Rede de Crianças e Adolescentes Comunicadores de Língua Portuguesa}

No ano de 2002, um dos principais financiadores da Fundação Casa Grande, o UNICEF, propôs um projeto de integração entre experiências do Brasil, Moçambique e Angola, na área de Comunicação e desenvolvimento, geridas por crianças e adolescentes. A proposta inicial previa intercâmbios de saberes entre os jovens produtores de conteúdos para rádios comunitárias ou educativas, apoiadas pela agência de cooperação internacional. A troca de conhecimentos, ademais de incrementar a qualidade dos produtos comunicacionais, previa o fortalecimento da autoestima dos envolvidos, os quais, excetuando-se as especificidades histórico-políticas dos países, convivem em um cenário de similares contingências.

O objetivo principal da rede é promover e fortalecer experiências de Comunicação coordenadas por crianças, adolescentes e jovens. Mais especificamente, pretende estimular a formação de uma rede solidarística de sujeitos sociais e comunidades que, tendo o idioma como principal elo e as incipientes condições estruturais, possam manter os jovens envolvidos em atividades protagonísticas, de ativismo social e cultural. É válido salientar que, a formação desta rede foi impulsionada pelo UNICEF. Se envolveram na empreitada três organizações da sociedade civil, uma de cada país.

Seis jovens de Nova Olinda estão envolvidos diretamente com seu funcionamento desde o início, estabelecendo contatos e produzindo materiais. Os demais participam de forma indireta e passiva, acompanhando a elaboração de peças de Comunicação ou mesmo através dos repasses de informações em reuniões institucionais periódicas.

\footnotetext{
${ }^{5}$ Entrevista concedida pelo jovem S.S. no dia 06 de janeiro de 2011, na cidade de Nova Olinda, Ceará.
}

Intercom - RBCC

São Paulo, v.35, n.2, p. 225-246, jul./dez. 2012 
Os seis jovens entrevistados para esta pesquisa atuaram de formas distintas ao longo dos oito anos de existência da rede internacional. Dois estiveram a cargo da produção de vídeos- documentários que mostram semelhanças e diferenças entre os três países; dois, por atuarem na Rádio Casa Grande FM, são responsáveis pela produção dos programas que são remetidos para Moçambique e Angola; os outros dois, por estarem na Editora, onde se desenvolvem as ações de Comunicação institucional, tiveram mais contatos com jovens de outros países, estabelecendo diálogos via ferramentas virtuais de Comunicação, a fim de manter a rede em funcionamento. Atualmente, as interações são quase inexistentes por motivos que, mais adiante, detalharemos.

Os contatos presenciais da Rede são escassos. As respostas ao roteiro de entrevistas nos apontam que apenas o coordenador da Fundação, Alemberg Quindins, esteve em Moçambique e Angola, onde ministrou oficinas de rádio e TV para os jovens africanos. Dois representantes de Moçambique também estiveram em Nova Olinda para conhecer presencialmente a experiência desenvolvida na cidade cearense. Assim, a Comunicação entre os jovens, desde o início, foi mediada pelas Tecnologias de Informação e Comunicação, assim como, pelos contatos e informações repassados pelos coordenadores das instituições envolvidas que conheceram a realidade dos outros países presencialmente.

Mídias sociais e programas de conversação são os meios de Comunicação mais utilizados para as interações entre os jovens Nova Olindenses, de Moçambique e de Angola. Os mais citados foram o Skype, o MSN e o e-mail. Os primeiros dão suporte aos diálogos pré-agendados. O último é utilizado, principalmente, para envio de dados como pequenos programas, trilhas e mesmo para contatos interpessoais. As interações na Rede de Crianças e Adolescentes Comunicadores de Língua Portuguesa aparecem inseridas no contexto da cultura da Internet e balizadas pelo modelo comunicacional contemporâneo vigente, o qual está vinculado às relações que tem na sua base componentes associados à globalização comunicacional, a ligação em rede dos media e às crescentes formas de interatividade. Nos diálogos via Skype e MSN, segundo as respostas, os recursos disponíveis eram utilizados em sua com- 
pletude: áudio, vídeo e texto. Para o jovem H.F., as ferramentas virtuais de Comunicação são fundamentais para a rede:

Se não tivesse essas ferramentas não teria acontecido nada. Cada vez mais a Internet tem se apresentado para nós como importante, por isso também já temos página no youtube, estamos no twitter e queremos colocar a nossa rádio na Web, mas a Internet por satélite aqui é muito ruim. Muitos dos meninos não sabiam utilizar bem a Internet, mas agora as coisas estão mudando (H.F., 2011) $)^{6}$.

A cultura da Internet se expande, em um movimento contínuo, em escala global, desde a década de 1990. Seu uso estabelece novas formas de interação, de linguagens e de práticas sociais. Há uma quebra de paradigmas tradicionais, expandindo as noções de território e tempo, assim como, de relações de poder, visto que todos podem ser produtores de conteúdo.

Foi possível perceber que o uso das tecnologias comunicacionais, de redes sociais virtuais e da convergência mediática faz parte do cotidiano dos jovens de Nova Olinda em diversas esferas. Quatro possuem computadores em casa e manejam diferentes sistemas operacionais (Mac, Linux e Windows); todos têm acesso diário à Internet, via Fundação ou alguma lan house; os seis possuem blogs e perfis no Orkut e Facebook, além de utilizarem o MSN e o Gtalk para trocas instantâneas de mensagens. O uso do Skype, em especial, foi incentivado pela participação na Rede, mas não é muito popular, tendo sido utilizado poucas vezes pelos entrevistados.

\section{Contingenciamento no uso das TICs}

Nem as tecnologias e nem mesmo as redes são redentoras. $\mathrm{O}$ fato dos jovens possuírem determinados bens materiais hi tech não significa que possuam plenas condições de uso. Ou seja, os celulares multifuncionais citados anteriormente, por exemplo, permitem acesso à Internet e infindas possibilidades de interação via áudio, vídeo e mensagens, no entanto os planos para estes serviços,

\footnotetext{
${ }^{6}$ Entrevista concedida por H.F. no dia 06 de janeiro de 2011, na cidade de Nova Olinda, Ceará
}

Intercom - RBCC

São Paulo, v.35, n.2, p. 225-246, jul./dez. 2012 
disponibilizados pelas operadoras de telefonia móvel são caros, o que os torna proibitivos para alguns contextos, em especial os populares. Assim, as novas configurações sociais estabelecidas no bojo da cultura da Internet também criam condições de exclusão.

La sociedad, concebida antes en términos de estratos y niveles, o distinguiéndose según identidades étnicas o nacionales, es pensada ahora bajo la metáfora de la red. Los incluidos son quienes están conectados, y sus otros son excluidos, quienes ven rotos sus vínculos al quedarse sin trabajo, sin casa, sin conexión. Estar marginado es estar desconectado (...) (CANCLINI, 2008, p.73).

É na própria tecnologia que está a primeira dificuldade de Comunicação com os jovens de outros países apontadas pelos entrevistados: são incipientes as condições de acesso à Internet em Nova Olinda. Na cidade, a Internet é via satélite e apresenta problemas de conexão. H.F., ao falar sobre as formas de troca de produtos na Rede, aponta a fragilidade:

Eles nos enviam alguns programas pela Internet, nós sempre enviamos produções de vídeo mas, no início, o contato era maior. Na maioria das vezes, agendávamos para que entrassem pela Internet, ao vivo, no Papo Cabeça. Muita gente daqui passou a entender melhor a realidade dos países africanos e muito da nossa história, que também é a história dos negros africanos que vieram para o Brasil. Mas é muito difícil. A Internet cai muito e depois a gente vai perdendo o ânimo (H.F., 2010) ${ }^{7}$.

A Rede de Crianças e Adolescentes Comunicadores de Língua Portuguesa ao apostar nas TICs como a única forma de Comunicação entre os jovens se tornou susceptível a descontinuidades e a problemas de funcionamento. A conjuntura de desigualdades no acesso à bens e serviços que envolve os jovens dos três países foi um ponto de mobilização - uma vez que o objetivo da articulação é fortalecer experiências para superação deste quadro, estimulando o protagonismo juvenil -, mas também de dispersão e enfraquecimento da iniciativa, visto que a requerida inclusão digital não é plena por empecilhos estruturais.

\footnotetext{
${ }^{7}$ Entrevista concedida por H.F. no dia 06 de janeiro de 2011, na cidade de Nova Olinda, Ceará.
} 
As respostas dos entrevistados reiteram que as mediações tecnológicas são importantes, mas cumprem um papel complementar. As estratégias presenciais de interação parecem ser imprescindíveis para a formação de laços de solidariedade e cooperação que caracterizam as redes sociais.

Para alguns momentos as tecnologias são boas, mas os encontros presenciais são mais importantes, eu acho. Trocar figurinhas de perto é mais fácil e mais legal (H.F., 2011) ${ }^{8}$.

$\mathrm{Eu}$ acho que a Internet não substitui os encontros presenciais, acho que complementa. Você pode conversar com uma pessoa pela Internet, mas nunca saberá se ela é como realmente quer dizer que é. Por uns minutos ou por um chat qualquer um pode mentir, fingir ser outra pessoa que nunca saberemos qual é a verdade. $\mathrm{O}$ fato da Internet nos deixar menos distantes não significa que estejamos perto (J.A., 2011) ${ }^{9}$.

\section{Conclusões}

A cultura da Internet promoveu uma redefinição dos padrões de interação entre diferentes partes do mundo, estimulando a adoção de novas linguagens e alterando os conceitos de tempo e espaço. Neste contexto, as redes são consideradas as mais adequadas metáforas do atual sistema: um conjunto de nós interconectados, flexíveis e adaptáveis às constantes mudanças, mas que apresentam dificuldades de funcionamento na medida em que sua composição se diversifica.

As aprendizagens e apropriações de ferramentas oriundas da dinâmica da Rede de Crianças e Adolescentes Comunicadores de Língua Portuguesa observadas parecem estar organizadas em três níveis que se complementam e se fundem em grande parte das respostas: o pessoal, vinculado às práticas cotidianas e perspectivas de futuro dos jovens; o profissional, fortemente associado às ações na Fundação Casa Grande; e o comunitário, que diz respeito ao impacto no desenvolvimento local de Nova Olinda. Dentre os achados de pesquisa estão:

\footnotetext{
${ }^{8}$ Entrevista concedida por H.F. no dia 06 de janeiro de 2011, na cidade de Nova Olinda, Ceará.

${ }^{9}$ Entrevista concedida por J.A. no dia 08 de janeiro de 2011, na cidade de Nova Olinda, Ceará.
} 
- A participação em uma rede social global, que adotou a Comunicação virtual como principal forma de diálogo entre seus participes, ampliou os usos das Tecnologias de Informação e Comunicação nas esferas pessoal e profissional dos jovens;

- Apesar do cenário de desigualdade no acesso às tecnologias, os entrevistados nesta pesquisa ampliaram, nos últimos oito anos, a sua rede de relacionamentos e interações sociais mediadas tecnologicamente. Isto se deve à inserção em redes sociais virtuais como Orkut e MSN, assim como, pela participação em outras redes movimentalistas internacionais;

- Os jovens estão trabalhando diretamente com as TICs, operando diversas linguagens operacionais (Windows, Linux, Mac) e softwares para produzir programas de rádios e documentários, entre outros;

- A inserção na Rede de Crianças e Adolescentes Comunicadores de Língua Portuguesa ampliou o desejo de conhecer novas culturas e viajar, influenciando na decisão de continuar atuando com produções na área de Comunicação;

- No manejo da programação da Rádio Casa Grande FM também foram inseridas novos programas virtuais que permitam maior interatividade e entrevistas, como o uso do Skype;

- A grade de programação radiofônica, a qual está muito associada às músicas, em especial a MPB, Jazz e Blues, ampliou o repertório musical através da incorporação de gêneros de Angola e Moçambique;

- A partir da experiência de intercâmbio com outros países, os jovens utilizam a Internet como forma de divulgação de suas produções e trabalhos principalmente via Youtube, Twitter e Site institucional;

- O conjunto das apropriações possibilita identificar que as mudanças empreendidas a partir da experiência estão mais vinculadas às formas de interatuar com outros jovens e com o mundo do que aos conteúdos que estes contatos proporcionam. 
As apropriações dos jovens e os novos usos que fazem das interações com outros países também impactou na comunidade em que vivem. Os jovens relatam que o estabelecimento de uma linha de trabalho com foco na participação em coletivos internacionais incentivou a realização de eventos em Nova Olinda, como mostras artísticas, que ampliaram a visibilidade do município e o número de turistas. Este dado fez com que o Ministério do Turismo concedesse, em 2009, o título de Cidade Indutora do Turismo Social e Comunitário. Por sua vez, disto derivam mais recursos para a gestão local investir na organização de espaços para comercialização de artesanato e em investimentos para dar visibilidade à região.

É possível, no entanto, observar que isto não é resultado apenas dos trabalhos com a Rede de Crianças e Adolescentes Comunicadores de Língua Portuguesa. Trata-se de um movimento processual de articulação de forças da comunidade e de fora dela. A Rede abriu caminhos para este fantástico mundo novo, mas não é a única responsável pelos resultados alcançados.

\section{Referências}

CANCLINI, Néstor García. Diferentes, desiguales y desconectados: mapas de la interculturalidad. Barcelona (Espanha): Gedisa Editorial, 2008.

CASTELLS, Manuel. A sociedade em rede. São Paulo: Editora Paz e Terra, 2009.

DIAS, Leila Christina. Os sentidos da rede: notas para uma discussão. In: DIAS, Leila Christina; SILVEIRA, Rogério Leandro Lima (ORG). Redes, sociedades e territórios. 2.ed. Santa Cruz do Sul: EDUNISC, 2007. p. 11 - 28.

GÓMEZ, Guillermo Orozco. Travesías de la recepción en América Latina. In: GÓMEZ, Guillermo Orozco. Recepción y mediaciones. Buenos Aires: Grupo Editorial Norma, 2002. p. 15-24.

LOPES, Maria Immacolata Vassallo de. Explorações metodológicas num estudo de recepção de telenovela. In: LOPES, Maria Immacolata V. de. Temas contemporâneos em Comunicação. São Paulo: Edicon/Intercom, 1997.

MARTIN-BARBERO, Jesús. Globalização comunicacional e transformação cultural. In: MORAES, Dênis (Org). Por uma outra Comunicação: mídia, mundialização cultural e poder. Rio de Janeiro: Editora Record, 2003. p. 57-86.

MARTÍN-BARBERO, Jesús. A mudança na percepção da juventude: sociabilidades, tecnicidades e subjetividades entre os jovens. In: BORELLI, Silvia

Intercom - RBCC

São Paulo, v.35, n.2, p. 225-246, jul./dez. 2012 
H.S.; FILHO, João Freire. Culturas juvenis no século XXI. São Paulo: Educ, 2008. p. $9-32$.

SANTOS, Boaventura de Sousa; NUNES, João Arriscado. Introdução: para ampliar o cânone do reconhecimento, da diferença e da igualdade. In:SANTOS, Boaventura Sousa. Reconhecer para libertar: os caminhos do cospomolitismo multicultura. Rio de Janeiro: Civilização Brasileira, 2003. p. 25-68.

SHERER-WARREN, Ilse. Redes sociais: trajetórias e fronteiras. In: DIAS, Leila C.; SILVEIRA, Rogério L.Lima (Org). Redes, sociedades e territórios. 2.ed. Santa Cruz do Sul: EDUNISC, 2007. p. 29 - 50.

TAUK SANTOS, Maria Salett; NASCIMENTO, Marta Rocha do. Desvendando o mapa noturno: análise da perspectiva das mediações nos estudos de recepção. In: SOUSA, Mauro Wilton de (org.). Recepção mediática e espaços públicos: novos olhares. São Paulo: Paulinas, 2006. p. 105-118.

WANDERLEY, Maria de Nazareth Baudel. Jovens rurais de pequenos municípios de Pernambuco: que sonhos para o futuro. IN: CARNEIRO, Maria José; CASTRO, Elisa Guaraná. Juventude Rural em perspectiva. Rio de Janeiro: Mauad, 2007. p. 21-34.

KNEWITZ, Anna Paula. Estudos culturais e cibercultura: um entrelaçamento teórico-metodológico necessário para pensar a recepção na Web. In: XVIII Encontro da Compós. Minas Gerais, jun. 2009. Anais do XVIII Encontro da Compós. Disponível em: softwarelivre.org/samadeu/recepcao-na-Web.pdf, acessado em 09 de abril de 2012, às 13 h20.

NOVA Olinda: dados sobre educação. IBGE. Brasília, 2008. Disponível em: http://www.ibge.gov.br/cidadesat/xtras/temas.php?nomemun $=$ Nova\%20Olind $\mathrm{a} \& \operatorname{codmun}=230920 \&$ tema $=$ educa $\&$ desc $=$ Ensino $\% 20$-el. $\& u f=c e \& r=2 \#$. Acesso em: 03 ago. 2010.

TAXA de analfabetismo em Nova Olinda, INEP. Brasília, 2009. Disponível em:http://ide.mec.gov.br//2008/gerarTabela.php. Acesso em: 03 ago. 2010.

MISSÃO da Fundação Casa Grande. Fundação Casa Grande. Nova Olinda, 2008. Disponível em: http://www.fundacaocasagrande.org.br/principal.php.

Acesso em: 24 fev.2010.

RESULTADOS iniciais do Censo 2010. IBGE. Brasília, 2010. disponíveis em: http://www.ibge.gov.br/censo2010/resultados_do_censo2010.php. Acesso em: 12 jan. 2011.

Recebido: 22.05.2012

Aceito: 30.09 .2012 